\title{
Factors influencing prescribing behaviour of physicians in Greece and Cyprus: results from a questionnaire based survey Mamas Theodorou1, Vasiliki Tsiantou ${ }^{2}$, Andreas Pavlakis', Nikos Maniadakis*3, Vasilis Fragoulakis³, Elpida Pavi² and John Kyriopoulos ${ }^{2}$
}

Address: ${ }^{1}$ Department of Health Economics \& Management, Open University of Cyprus, Cyprus, ${ }^{2}$ Department of Health Economics, National School of Public Health, Athens, Greece and ${ }^{3}$ Department of Health Services Organisation \& Management, National School of Public Health, 196 Alexandras Avenue, 11522 Athens, Greece

Email: Mamas Theodorou - m.theodorou@ouc.ac.cy; Vasiliki Tsiantou - vtsiantou@nsph.gr; Andreas Pavlakis - a.pavlakis@ouc.ac.cy; Nikos Maniadakis* - nmaniadakis@yahoo.com; Vasilis Fragoulakis - fragoulakis@ika.gr; Elpida Pavi - epavi@nsph.gr; John Kyriopoulos - nsphkyr@ath.forthnet.gr

* Corresponding author

Published: 20 August 2009

BMC Health Services Research 2009, 9:150 doi:10.1186/1472-6963-9-150

This article is available from: http://www.biomedcentral.com/1472-6963/9/150

(C) 2009 Theodorou et al; licensee BioMed Central Ltd.

This is an Open Access article distributed under the terms of the Creative Commons Attribution License (http://creativecommons.org/licenses/by/2.0), which permits unrestricted use, distribution, and reproduction in any medium, provided the original work is properly cited.
Received: 2 October 2008

Accepted: 20 August 2009

\begin{abstract}
Background: Over the past few decades, drug and overall healthcare expenditure have risen rapidly in most countries. The present study investigates the attitudes and the factors which influence physician prescribing decisions and practice in Greece and Cyprus.

Methods: A postal questionnaire was developed by researchers at the Department of Health Economics at the National School of Public Health in Greece, specifically for the purposes of the study. This was then administered to a sample of I,463 physicians in Greece and 240 physicians in Cyprus, stratified by sex, specialty and geographic region.

Results: The response rate was $\mathbf{8 2 . 3 \%}$ in Greece and $\mathbf{8 0 . 4 \%}$ in Cyprus. There were similarities but also many differences between the countries. Clinical effectiveness is the most important factor considered in drug prescription choice in both countries. Greek physicians were significantly more likely to take additional criteria under consideration, such as the drug form and recommended daily dose and the individual patient preferences. The list of main sources of information for physicians includes: peer-reviewed medical journals, medical textbooks, proceedings of conferences and pharmaceutical sales representatives. Only half of prescribers considered the cost carried by their patients. The majority of doctors in both countries agreed that the effectiveness, safety and efficacy of generic drugs may not be excellent but it is acceptable. However, only Cypriot physicians actually prescribe them. Physicians believe that new drugs are not always better and their higher prices are not necessarily justified. Finally, doctors get information regarding adverse drug reactions primarily from the National Organisation for Medicines. However, it is notable that the majority of them do not inform the authorities on such reactions.
\end{abstract}

Conclusion: The present study highlights the attitudes and the factors influencing physician behaviour in the two countries and may be used for developing policies to improve their choices and hence to increase clinical and economic effectiveness and efficiency. 


\section{Background}

Over the past few decades, pharmaceutical expenditure has risen rapidly in most western countries and this has been a reason for concern to policymakers, who have reacted with healthcare reforms and measures to guarantee the sustainability of their health care systems [1]. In the countries of the Organisation for Economic Cooperation and Development (OECD), pharmaceutical expenditure accounts, on average, for about $1.5 \%$ of the Gross Domestic Product (GDP). It is notable however that it grows, in real terms, by $4.6 \%$ annually, which is higher than the growth rate of total healthcare expenditure or the growth rate of GDP [2]. Alongside the concern regarding the growth of pharmaceutical expenditure, there is also a increasing concern regarding irrational, inappropriate, or sometimes even harmful prescribing $[3,4]$. The latter matter has two manifestations. On the one hand, there is plenty of evidence from observational or experimental studies that, for several reasons many of which have been identified, eligible patients are not always prescribed the pharmaceutical therapies indicated for their condition. On the other hand, there is also evidence about over and misuse of pharmaceutical products. The consequence of the above can be the loss of health and quality of life benefit for patients and society and the increase of health care expenditure [5]. Thus, for health and economic reasons, it is important to follow the recommended optimal and established drug prescription guidelines.

In this context, a lot of research is trying to analyse and to understand the factors which influence physician prescribing decisions and practice. The related literature suggests several factors that may have a role in influencing the prescribing behaviour of physicians [6-9]. Some factors are fixed and they do not offer any opportunity for modification and improvements in prescribing behaviour. Such factors for instance include, the age and sex of the physician or the patient, the socio-economic characteristics of the practicing area or the reimbursement status of therapy $[10,11]$. On the other hand, there are factors which can be influenced and in turn cause a modification to the prescribing behaviour of physicians. Such factors may be the under and post graduate education and the experience of the physician, various social factors, the number of practitioners in a practice and others [12-15].

It is notable that no other study has attempted so far to analyse the prescribing behaviour and its determinants amongst Greek or Cypriot primary care physicians. Therefore, we carried out a survey in order to investigate the prescribing attitudes of physicians in these two countries and in the present paper we present the main survey results. The paper outlines in a comparative and detailed way the main factors influencing the decision making and the drug prescription choices of physicians in the two coun- tries. More specifically, it reveals the criteria which justify prescription choice, the sources of physician information, the attitudes towards generic or new innovative drugs, the importance of the drug cost in the decision, etcetera. This information can help policy makers to identify the measures needed to improve the effectiveness of health policy and consequently it can contribute towards a greater economic and clinical efficiency and effectiveness in the two countries under consideration.

\section{Organisation of Health System in Greece and in Cyprus}

The Greek health care system has characteristics from both the Beveridge (Social Security) and the Bismarck (Social Insurance) health organisation model. Specifically, a National Health Service (NHS) was established in 1983, with the aim to provide on behalf of the state health care services to all citizens. In this context, services are provided by public secondary and tertiary care hospitals and by primary care units, which are located in semi-urban and rural areas. There are also a few thousand primary care physicians doing after graduation compulsory training in rural areas. The NHS is funded by taxation and by payments coming from many existing Public Insurance Sickness Funds. However, it is notable that the Sickness Funds also operate on their own several primary care health units and hospitals. Finally, alongside the above there is a significant in size private health care sector, comprising freelancing or contracted physicians, diagnostic centres and hospitals. There are no general practitioners, to act as gatekeepers to the healthcare system in Greece. Thus, regarding their health problem, patients can consult with any physician within the primary or secondary health care system. In Cyprus healthcare delivery depends on both public and private health units as well. The public sector is mostly responsible for the provision of secondary and tertiary care and the private sector is responsible for the provision of primary health care services. It is notable that in this country as well there is no gate-keeping system at present, meaning that patients are free to select and consult with any physician of their choice [16].

\section{Methods}

A questionnaire was developed by the Department of Health Economics at the National School of Public Health in Greece, specifically for the purposes of the survey. The questionnaire is divided into seven different sections: the first is designed to investigate the determinants of physician prescribing behaviour and their main sources of information; the second reflects their opinion about the cost of pharmaceuticals to the patient; the third section focuses on attitudes towards the prescription of generics; the fourth section reflects attitudes towards new pharmaceutical products; the fifth section is about adverse drug reactions and safety; the sixth section focuses on pharmaceutical company sales representatives; and the last sec- 
tion includes questions about the demographic characteristics of the person answering. In total, the questionnaire included 47 semi-closed questions. It was piloted to a group of 217 physicians in Greece in the period between the November of 2006 and January of 2007. The physicians who participated in the pilot study made significant comments towards the improvement of the instrument and all of their recommendations were taken into consideration and were incorporated in the final questionnaire.

The proportional stratified sampling technique was used to draw a sample, on the basis of physician geographical region, specialty and sex. Excluded from the sample were physicians who were not authorised to prescribe, either because they were still interns or because they belonged to a specialty that is not permitted to prescribe (radiology, nuclear medicine, microbiology, haematology, anaesthesiology, forensic medicine). In Greece, a sample of 1,463 physicians was randomly selected for the purpose of the study and in Cyprus the questionnaire was sent to 240 physicians also randomly selected in a similar manner. In both countries, the final questionnaire, a cover letter and a prepaid return envelope were mailed to the physicians from the $1^{\text {st }}$ of April 2007 to the $30^{\text {th }}$ of May 2007. The study is non interventional and it does not involve patients and hence no ethical approval was needed. Nonetheless, it was undertaking according to the ethical standards and procedures set for this type of research in both countries and academic institutions involved. Data collection followed by quality control, codification, recording and statistical analysis with SPSS (ver15.0).

\section{Results}

\section{Demographic characteristics}

1,204 physicians from Greece participated in the study (response rate: 82.3\%) and 193 in Cyprus (response rate: $80.4 \%$ ). In Greece $79.9 \%$ were male and $20.1 \%$ female, whilst in Cyprus the percentages were $69.8 \%$ and $30.2 \%$, respectively. As indicated in Table 1, almost half of the participants in Cyprus (46.8\%) were between 41-50 years of age, whilst in Greece the largest proportion of participants (35.9\%) were aged between 51 and 60 years, thus representing an older and more experienced sample. In terms of specialties, in Greece the largest proportion of the participants were pathologists $(14.1 \%)$, followed by paediatricians $(10.3 \%)$ and gynaecologists $(9.1 \%)$, whilst in Cyprus the percentages were as following: paediatricians (17.1\%), pathologists $(9.6 \%)$, gynaecologists and surgeons $(9.1 \%)$. A larger percentage of Cypriot participants (49.2\% versus $26.7 \%$ ) had a Master of Science (M.Sc) degree, whilst a larger proportion of Greek physicians (50.9\% versus $30.6 \%$ ) had participated in a publication during the previous five years. The great majority of doctors in both countries attend at least one conference per
Table I: Physicians characteristics in Greece and Cyprus

\begin{tabular}{|c|c|c|}
\hline & $\begin{array}{c}\text { Greece } \\
(\%)\end{array}$ & $\begin{array}{c}\text { Cyprus } \\
\text { (\%) }\end{array}$ \\
\hline \multicolumn{3}{|l|}{ Sex } \\
\hline Male & 79.9 & 69.8 \\
\hline Female & 20.1 & 30.2 \\
\hline \multicolumn{3}{|l|}{ Age } \\
\hline $30-40$ & 10.2 & 17.4 \\
\hline $4 I-50$ & 33.6 & 46.8 \\
\hline $51-60$ & 35.9 & 33.2 \\
\hline $61+$ & 20.3 & 2.6 \\
\hline \multicolumn{3}{|l|}{ Practicing years } \\
\hline $1-5$ & 1.5 & 4.8 \\
\hline $6-10$ & 4.6 & 11.7 \\
\hline $11-15$ & 15.4 & 21.8 \\
\hline $16-20$ & 18.0 & 29.9 \\
\hline $21+$ & 60.5 & 38.8 \\
\hline \multicolumn{3}{|l|}{ Specialty } \\
\hline Pathologist & 14.1 & 9.6 \\
\hline Paediatrician & 10.3 & 17.1 \\
\hline Gynaecologist & 9.1 & 9.1 \\
\hline Cardiologist & 8.6 & 7.5 \\
\hline Neurologist & 7.3 & - \\
\hline Surgeon & 6.9 & 9.1 \\
\hline Other & 43.7 & 47.6 \\
\hline \multicolumn{3}{|l|}{ Education/Training } \\
\hline Post graduate & 26.7 & 49.2 \\
\hline Continuous education & 50.1 & 56.5 \\
\hline At least one conference/year & 88.8 & 77.7 \\
\hline At least one publication $/ 5$ years & 50.9 & 30.6 \\
\hline \multicolumn{3}{|l|}{ Employment Sector } \\
\hline Private & 52.8 & 35.2 \\
\hline Public & 15.7 & 64.2 \\
\hline Social insurance & 2.6 & - \\
\hline Multiple & 27.3 & 0.5 \\
\hline \multicolumn{3}{|l|}{ Use of PC } \\
\hline High & 23.1 & 19.9 \\
\hline Satisfactory & 33.3 & 52.9 \\
\hline Moderate & 26.5 & 19.4 \\
\hline None & 17.1 & 7.9 \\
\hline
\end{tabular}

year. In terms of computer acquaintance the Cypriot physician cohort appears to have a slight advantage. However, it needs to be noted that physicians in both countries are more computer literate than the general population.

\section{Influential factors}

As mentioned earlier, the first part of the questionnaire was intended to investigate the criteria which physicians take into consideration when making prescribing decisions and their sources of information regarding advances 
in pharmaceuticals. As indicated in Table 2, clinical effectiveness is the most important factor, reaching 94.85\% and $93.26 \%$ in Greece and Cyprus, respectively and there was no statistically significant difference between the two. However, in Greece the drug form, the recommended daily dose, and patient's own preferences appear to be more important in the selection of the therapy. With regard to the cost of drugs to patients, about sixty percent of physicians take it less or more seriously into considera- tion when prescribing and there are no major differences between the two countries. In particular, cost is important to $46.59 \%$ and $51.30 \%$ and highly important to $15.95 \%$ and $11.40 \%$, of Greek and Cypriot physicians respectively. The same picture applies in relation to patient insurance coverage, where about $69.97 \%$ and $64.77 \%$ of physicians take it into account in Greece and Cyprus, respectively.

Table 2: Prescribing behavior of physicians

Proven clinical effectiveness Pharmaceutical delivery mode Recommended daily dose

Cost to the patient Patient preference Other

Publications in medical journals Medical textbooks

Medical congress announcements Pharmaceutical sales representatives Medical libraries and internet data bases

Others

Dose

Adverse drug reactions Interactions with other substances Provision during pregnacy Provision during breast feeding Liver-renal disorders Chronic disease Important

Not very important

Not at all important

Very much

Enough

Rather influence me

Almost not all

Not at all
Which constitutes for you the basic criterion for selecting a drug?

\begin{tabular}{cccc}
\hline Greece & Cyprus & Difference & P-value \\
$94.85 \%$ & $93.26 \%$ & $1.59 \%$ & 0.392 \\
$38.21 \%$ & $9.84 \%$ & $28.37 \%$ & 0.000 \\
$35.55 \%$ & $4.15 \%$ & $31.40 \%$ & 0.000 \\
$41.86 \%$ & $8.29 \%$ & $33.57 \%$ & 0.000 \\
$11.05 \%$ & $0.52 \%$ & $10.53 \%$ & 0.000 \\
$2.49 \%$ & $3.63 \%$ & $-1.14 \%$ & 0.406 \\
\hline
\end{tabular}

Which sources do you take into account in justifying your prescription choices?

\begin{tabular}{cccc}
\hline Greece & Cyprus & Difference & p-value \\
$73.75 \%$ & $58.55 \%$ & $15.20 \%$ & 0.000 \\
$60.71 \%$ & $44.04 \%$ & $16.67 \%$ & 0.000 \\
$70.27 \%$ & $69.43 \%$ & $0.84 \%$ & 0.813 \\
$51.99 \%$ & $61.14 \%$ & $-9.15 \%$ & 0.016 \\
$29.49 \%$ & $28.50 \%$ & $0.99 \%$ & 0.757 \\
$3.41 \%$ & $0.52 \%$ & $2.89 \%$ & 0.000 \\
\hline
\end{tabular}

For what reasons do you search further information from the above sources on your prescription choice?

\begin{tabular}{cccc}
\hline Greece & Cyprus & Difference & P-value \\
$43.02 \%$ & $41.45 \%$ & $1.57 \%$ & 0.668 \\
$81.48 \%$ & $77.20 \%$ & $4.28 \%$ & 0.182 \\
$67.11 \%$ & $63.21 \%$ & $3.90 \%$ & 0.292 \\
$53.99 \%$ & $56.48 \%$ & $-2.49 \%$ & 0.514 \\
$50.91 \%$ & $44.56 \%$ & $6.35 \%$ & 0.097 \\
$49.25 \%$ & $55.96 \%$ & $-6.71 \%$ & 0.079 \\
$43.44 \%$ & $21.24 \%$ & $22.20 \%$ & 0.000
\end{tabular}

How important is the cost of drug in your prescription selection?

\begin{tabular}{cccc}
\hline Greece & Cyprus & Difference & P-value \\
$15.95 \%$ & $11.40 \%$ & $4.55 \%$ & 0.066 \\
$46.59 \%$ & $51.30 \%$ & $-4.71 \%$ & 0.218 \\
$25.83 \%$ & $30.05 \%$ & $-4.22 \%$ & 0.225 \\
$11.63 \%$ & $7.25 \%$ & $4.38 \%$ & 0.035 \\
\hline
\end{tabular}

To which extend does the existence of patient insurance coverage, influence your selection?

\begin{tabular}{cccc}
\hline Greece & Cyprus & Difference & p-value \\
$20.97 \%$ & $14.51 \%$ & $6.46 \%$ & 0.022 \\
$31.11 \%$ & $23.32 \%$ & $7.79 \%$ & 0.021 \\
$17.89 \%$ & $26.94 \%$ & $-9.05 \%$ & 0.000 \\
$17.14 \%$ & $20.73 \%$ & $-3.59 \%$ & 0.239 \\
$12.90 \%$ & $14.51 \%$ & $-1.61 \%$ & 0.548
\end{tabular}




\section{Information sources}

Physicians derive information to guide and justify their prescription choices mainly from medical journals, medical textbooks, proceedings of medical congresses, sales representatives and the internet. Nonetheless, there are some differences between the two countries. Specifically, Greek doctors rely more on scientific publications and medical textbooks and less on pharmaceutical representatives. Analytically, medical journals and textbooks are preferred by $73.75 \%$ and $60.71 \%$ of Greek doctors, respectively, compared to $58.55 \%$ and $44.04 \%$ of Cypriots. On the other hand, pharmaceutical representatives are preferred as an information source by $61.14 \%$ of Cypriot doctors compared to $51.99 \%$ of Greeks. Physicians are looking for information on the above sources mainly regarding the recommended dose of drugs, their potential side effects, their use during pregnancy and breast feeding and their use in the presence of chronic renal or liver disease. There are no significant differences between the two countries in relation to the type of enquired information.

\section{Generic drug prescribing}

Table 3 contains information regarding the responses of physicians in relation to generic drug use. It is noteworthy that about half of doctors in Greece find generic drugs excellent or satisfactory in terms of efficacy, safety and effectiveness (51.25\%, 54.98\% and 52.41\% respectively). However, only $25.20 \%$ of them prescribe generic drugs

Table 3: Attitudes of physicians towards generic prescribing

\begin{tabular}{|c|c|c|c|c|}
\hline & \multicolumn{4}{|c|}{ What do you think about the quality of generic drugs in comparison to their branded ones? } \\
\hline & Greece & Cyprus & Difference & p-value \\
\hline Excellent & $4.71 \%$ & $3.11 \%$ & $1.60 \%$ & 0.240 \\
\hline Satistactory & $46.54 \%$ & $56.99 \%$ & $-10.45 \%$ & 0.006 \\
\hline Average & $31.92 \%$ & $32.64 \%$ & $-0.72 \%$ & 0.842 \\
\hline Rather bad & $10.29 \%$ & $5.18 \%$ & $5.11 \%$ & 0.005 \\
\hline Bad & $6.54 \%$ & $2.07 \%$ & $4.47 \%$ & 0.000 \\
\hline
\end{tabular}

What do you think about the safety of generics in comparison to their branded ones?

\begin{tabular}{|c|c|c|c|c|}
\hline & \multicolumn{4}{|c|}{ What do you think about the safety of generics in comparison to their branded ones? } \\
\hline & Greece & Cyprus & Difference & p-value \\
\hline Excellent & $5.31 \%$ & $6.22 \%$ & $-0.91 \%$ & 0.614 \\
\hline Satistactory & $49.57 \%$ & $61.66 \%$ & $-12.09 \%$ & 0.001 \\
\hline Average & $29.76 \%$ & $26.42 \%$ & $3.34 \%$ & 0.326 \\
\hline Rather bad & $8.99 \%$ & $4.66 \%$ & $4.33 \%$ & 0.011 \\
\hline Bad & $6.38 \%$ & $1.04 \%$ & $5.34 \%$ & 0.000 \\
\hline
\end{tabular}

What do you think about the effectiveness of generics in comparison to their branded ones?

Excellent

Satistactory

Average

Rather bad

Bad

\begin{tabular}{|c|c|c|c|}
\hline \multicolumn{4}{|c|}{ What do you think about the effectiveness of generics in comparison to their branded ones? } \\
\hline Greece & Cyprus & Difference & p-value \\
\hline $5.79 \%$ & $2.59 \%$ & $3.20 \%$ & 0.015 \\
\hline $46.62 \%$ & $59.59 \%$ & $-12.97 \%$ & 0.001 \\
\hline $33.49 \%$ & $32.12 \%$ & $1.37 \%$ & 0.690 \\
\hline $8.40 \%$ & $3.11 \%$ & $5.29 \%$ & 0.000 \\
\hline $5.69 \%$ & $2.59 \%$ & $3.10 \%$ & 0.021 \\
\hline \multicolumn{4}{|c|}{ How often do you prescribe a generic product instead of a branded one? } \\
\hline Greece & Cyprus & Difference & p-value \\
\hline $3.65 \%$ & $13.99 \%$ & $-10.34 \%$ & 0.000 \\
\hline $21.55 \%$ & $52.85 \%$ & $-31.30 \%$ & 0.000 \\
\hline $47.26 \%$ & $27.98 \%$ & $19.28 \%$ & 0.000 \\
\hline $27.54 \%$ & $5.18 \%$ & $22.36 \%$ & 0.000 \\
\hline \multicolumn{4}{|c|}{ Do you think it is feasible to implement a prescribing system based on the INN? } \\
\hline Greece & Cyprus & Difference & p-value \\
\hline $15.21 \%$ & $17.62 \%$ & $-2.41 \%$ & 0.397 \\
\hline $37.62 \%$ & $39.38 \%$ & $-1.76 \%$ & 0.631 \\
\hline $30.60 \%$ & $32.64 \%$ & $-2.04 \%$ & 0.567 \\
\hline $16.56 \%$ & $10.36 \%$ & $6.20 \%$ & 0.011 \\
\hline
\end{tabular}

Very often

Often

Rarely

Hardly ever

Do you think it is feasible to implement a prescribing system based on the INN?

Very feasible

Feasible

Rather impossible

Impossible

\section{$15.21 \%$}

$30.60 \%$
$17.62 \%$

$32.64 \%$ 
often or very often. On the other hand, Cypriots appear to have a more positive view regarding generic drugs. In particular, about $60.10 \%, 67.88 \%$ and $62.18 \%$ of physicians respectively find their efficacy, safety and effectiveness excellent or satisfactory. Finally, regarding the feasibility of prescribing based on drug substance (International Non-proprietary Name, INN) only, $37.62 \%$ and $15.21 \%$ of Greek physicians consider it rather feasible or very feasible, respectively, while the respective figures for Cypriot doctors are $39.38 \%$ and $17.62 \%$.

\section{New drug prescribing}

Table 4 presents information regarding attitudes in relation to new drugs. The majority, $82.11 \%$, of physicians in Greece believe that a higher price does not necessarily imply better patient outcomes. This percentage is somewhat lower, 63.21\%, in Cyprus and there are statistically significant differences between the two countries. There are also differences in relation to the perceptions of new drug effectiveness. More specifically, only $62.35 \%$ of Greek physicians believe that they are more effective, whilst the corresponding number amongst Cypriot doctors is $85.49 \%$. Finally, regarding the sources of information about new product launches, these mainly include medical journals, congresses and sales representatives and secondarily scientific medical societies and the internet.

\section{Adverse drug reactions and safety}

Finally, Table 5 presents information regarding physician attitudes towards safety issues. As indicated by the finding, physicians get information about side effects primarily from the National Organisation for Medicines and secondarily from the internet, pharmaceutical companies, colleagues, and the media. In Cyprus the National Drug Agency and colleagues appear to have a less important role. Side effects appear in both countries to be a major cause of prescription choice modification, as more than $90 \%$ of doctors declare that they change their prescription patterns in cases of side effects. However, that $46.68 \%$ of doctors in Greece declared that they had not encountered any side effect during the two years prior to the study. It is also noteworthy that the majority of doctors do not inform the authorities about their own cases of side effects.

\section{Discussion}

According to the present analysis, the Greek and Cypriot physicians are well educated and participate frequently in medical conferences. Furthermore, Greek doctors appear to have a high publication activity compared to their Cypriot colleagues. This could be partly explained by the fact that there are many university hospitals and also several medical journals in Greece. Our results indicate that there are similarities but also differences between physicians in Greece and Cyprus regarding the basic criteria upon which

Table 4: Attitudes of physicians towards innovation

\begin{tabular}{|c|c|c|c|c|}
\hline & \multicolumn{4}{|c|}{ In your opinion, does the high price of a new product implies also better effectiveness? } \\
\hline & Greece & Cyprus & Difference & p-value \\
\hline Absolutely & $2.90 \%$ & $4.15 \%$ & $-1.25 \%$ & 0.395 \\
\hline Enough & $14.99 \%$ & $32.64 \%$ & $-17.65 \%$ & 0.000 \\
\hline Not really & $49.23 \%$ & $55.96 \%$ & $-6.73 \%$ & 0.079 \\
\hline Almost not & $10.48 \%$ & $4.66 \%$ & $5.82 \%$ & 0.001 \\
\hline \multirow[t]{3}{*}{ Not at all } & $22.40 \%$ & $2.59 \%$ & $19.81 \%$ & 0.000 \\
\hline & \multicolumn{4}{|c|}{$\begin{array}{l}\text { Generally, what do you think about the effectiveness of new drug products in comparison to the older ones already } \\
\text { on the market? }\end{array}$} \\
\hline & Greece & Cyprus & Difference & p-value \\
\hline Clearly more effective & $18.73 \%$ & $24.35 \%$ & $-5.62 \%$ & 0.084 \\
\hline Rather more effective & $43.62 \%$ & $61.14 \%$ & $-17.52 \%$ & 0.000 \\
\hline Do not differ significantlly & $30.15 \%$ & $14.51 \%$ & $15.64 \%$ & 0.000 \\
\hline \multirow[t]{3}{*}{ Do not differ at all } & $7.49 \%$ & $0.00 \%$ & $7.49 \%$ & 0.000 \\
\hline & \multicolumn{4}{|c|}{ Which sources do you consult in order to get information for the launch of new drugs? } \\
\hline & Greece & Cyprus & Difference & p-value \\
\hline Scientific journals & $78.99 \%$ & $76.68 \%$ & $2.31 \%$ & 0.477 \\
\hline Medical congresses & $75.10 \%$ & $7.25 \%$ & $63.85 \%$ & 0.000 \\
\hline $\begin{array}{l}\text { Pharmaceutical } \\
\text { representatives }\end{array}$ & $77.33 \%$ & $88.08 \%$ & $-10.75 \%$ & 0.000 \\
\hline Scientific medical societies & $38.87 \%$ & $51.30 \%$ & $-12.43 \%$ & 0.001 \\
\hline Internet & $30.32 \%$ & $41.45 \%$ & $-11.13 \%$ & 0.003 \\
\hline
\end{tabular}


Table 5: Attitudes of physicians towards safety

\begin{tabular}{|c|c|c|c|c|}
\hline & \multicolumn{4}{|c|}{ Which sources do you consult in order to get informed about the ADRs of a drug? } \\
\hline & Greece & Cyprus & Difference & p-value \\
\hline National Medicines Organization & $65.70 \%$ & $48.70 \%$ & $17.00 \%$ & 0.000 \\
\hline Internet & $33.06 \%$ & $37.82 \%$ & $-4.76 \%$ & 0.200 \\
\hline Pharmaceutical representatives & $42.61 \%$ & $41.97 \%$ & $0.64 \%$ & 0.866 \\
\hline Media & $16.86 \%$ & II.92\% & $4.94 \%$ & 0.052 \\
\hline Colleagues & $38.54 \%$ & $21.24 \%$ & $17.30 \%$ & 0.000 \\
\hline \multirow[t]{3}{*}{ Other } & $4.32 \%$ & $11.40 \%$ & $7.08 \%$ & 0.001 \\
\hline & \multicolumn{4}{|c|}{ The appearance of ADRs affects your prescribing decision? } \\
\hline & Greece & Cyprus & Difference & p-value \\
\hline Very much & $51.21 \%$ & $43.01 \%$ & $8.20 \%$ & 0.030 \\
\hline A lot & $43.13 \%$ & $47.15 \%$ & $-4.02 \%$ & 0.300 \\
\hline A little & $4.91 \%$ & $9.84 \%$ & $-4.93 \%$ & 0.026 \\
\hline \multirow[t]{3}{*}{ Not at all } & $0.75 \%$ & $0.00 \%$ & $0.75 \%$ & 0.000 \\
\hline & \multicolumn{4}{|c|}{ How many times have an ADR appeared in your patients in the past two years? } \\
\hline & Greece & Cyprus & Difference & p-value \\
\hline None & $46.68 \%$ & $8.81 \%$ & $37.87 \%$ & 0.000 \\
\hline $\mathrm{I}-5$ times & $46.26 \%$ & $57.51 \%$ & $-11.25 \%$ & 0.004 \\
\hline $6-10$ times & $5.04 \%$ & $19.69 \%$ & $-14.65 \%$ & 0.000 \\
\hline \multirow[t]{3}{*}{ More } & $2.02 \%$ & $13.99 \%$ & $-11.97 \%$ & 0.000 \\
\hline & \multicolumn{4}{|c|}{ For such cases did you send a "yellow card*" to inform the authorities? } \\
\hline & Greece & Cyprus & Difference & p-value \\
\hline Yes & $37.43 \%$ & II.92\% & $25.51 \%$ & 0.000 \\
\hline No & $62.57 \%$ & $88.08 \%$ & $-25.51 \%$ & 0.000 \\
\hline
\end{tabular}

* Yellow card is a form that needs to be filled by the physician if side effects appear in order to inform the authorities.

they select a pharmaceutical treatment. Particularly, the findings show that drug clinical effectiveness is the most important factor considered by physicians when they prescribe drugs. However, pharmaceutical form, recommended daily dose, and patient own preferences are taken into consideration more by Greek physicians compared to their Cypriots colleagues. Furthermore, doctors in both countries declare that they are sensitive to the economic burden imposed upon patients and the health system in general. It is notable that, although Cypriot physicians claim that the cost of the drug and insurance coverage are important factors during prescription, in fact they do not consider cost as one of the most important criteria for prescription choice.

The results of our study show that there are differences between the two countries regarding the sources of information. Specifically, Greek doctors claim to acquire more information from publications (journals, proceedings of conferences and textbooks) and less information from pharmaceutical sales representatives. The opposite happens in Cyprus, where proceedings of conferences and information from sales representatives are in the leading places, followed by publications. The classification of these information sources is different in the case of information regarding new drugs and adverse drug reactions. Specifically, in the case of new drugs, sales representatives are the first source of information in Cyprus and the second in Greece, right after scientific or medical journals. These data are consistent with those from other studies, where it has been also shown that pharmaceutical sales representatives are highly influential on decisions to prescribe new drugs $[17,18]$.

Regarding opinions about generics and generic prescribing there are some differences between physicians in the two countries. In Greece doctors seem more cautious about the effectiveness, safety and efficacy of generic drugs, and as a result they do not prescribe generic drugs as a means to curtail expenditure. This is not so much the case in Cyprus, where doctors have a greater trust in generic drugs and prescribe them to a greater degree. However, in any case it needs to be stressed that, the percentage of physicians who believe that the quality of generics is excellent, is very small in both countries. This finding could indicate that physicians do not trust the process of 
approval and certification for generic products. The pessimistic and negative view in Greece needs further investigation in order to be addressed, as generic substitution is a major cost containment measure in most countries. Perhaps the low generic drug use in this country can be explained through the combination of several factors. As noted above a low generic quality perception prevails. This is combined with no major price differentials between branded and generic drugs, which eliminates the financial motive for the substitution. Furthermore, in Greece there are no financial incentives to motivate physicians to prescribe generics and to promote the generic market.

Finally, in the case of adverse drug reactions physicians are informed primarily by the National Organisation of Medicines and secondly by sales representatives. This is expected since the National Organisation of Medicines is responsible for the assessment of safety and the pharmacovigilance of medicinal products. Even though adverse drug reactions may not appear very often, they do have a profound effect on a physician prescribing patterns, so doctors seek information in order to be protected and prepared. It is notable, however, that when they encounter such problems physicians rarely inform the authorities accordingly, perhaps because they do not want to acknowledge the fact that their patients had side effects, or they do not evaluate the side effect as important. This finding is confirmed by data from the National Organisation for Medicines (EOF) in Greece. According to the Organisation, the reports about adverse drug reactions come mainly from pharmaceutical companies and from hospitals and to a much lesser degree from individual physicians [19]. For this reason, a campaign is under way in Greece aiming towards motivating more physicians to fill out the yellow card when they encounter an adverse drug reaction.

In conclusion, the findings of this study are in line to those of other published studies regarding physician prescribing behaviour and attitudes. More specifically, the issues of drug cost and patient insurance coverage concern the majority of physicians, who take these factors into consideration during their prescribing decisions. Results from a qualitative study in Denmark showed that drug price was considered an important factor influencing prescribing decision. Additionally, pharmaceutical industry sales representatives influenced physicians significantly [20]. Reichert at al showed in their study that physicians felt the cost of medicines to be an important criterion in prescription choice and this was even more important when patients were not insured [21]. In addition, our results are comparable to those of two other studies regarding opinions about generics and generic substitution [22,23]. Finally, a study that was carried out in 2005 in New Zealand, regarding the information sources which are mostly used by physicians, had similar results to our own. It showed that publications and pharmaceutical sales representatives were the most popular sources of information and that internet-based sources were used by half of the participants [24].

The present study is subject to all limitations that apply to surveys where postal questionnaires are used as a tool to extract data [25]. Nonetheless, the high response rate in both countries may allow us to believe that the study was successful. Another limitation is the lack of distinction between primary and secondary care physicians, which would have allowed a better comparison with other studies in this field. However, this parameter was not taken into account during the study design because, as mentioned at the beginning of this paper, Greece and Cyprus have no gate-keeping systems and patients have free access to every physician of every specialty and level of care.

\section{Conclusion}

The present article provides valuable information regarding the prescribing behaviour of doctors in Greece and Cyprus. Further analysis will help us to understand further the association between prescription choices and physician characteristics. These insights will help policy makers in both countries to develop measures which could be used to achieve to greater clinical effectiveness and economic efficiency from drug prescribing.

\section{Competing interests}

The authors declare that they have no competing interests.

\section{Authors' contributions}

MT, VT, AP, JK and EP designed and coordinated the study in Greece and Cyprus, whilst VF and NM undertook the analysis of data and the writing of the manuscript. All authors read and approved the final manuscript.

\section{Acknowledgements}

The authors acknowledge the contribution of Philip Lees, Technical Editor, Hellenic Journal of Cardiology, in the editing of the article.

\section{References}

I. Mossialos E, Walley T, Mrazek M: Regulating pharmaceuticals in Europe: an overview. In Regulating pharmaceuticals in Europe: striving for efficiency, equity and quality Edited by: Mossialos E, Mrazek M, Walley T. European Observatory on Health Systems and Policies Series. McGraw-Hill Education, Maidenhead, UK, Open University Press; 2004.

2. Organisation for Economic Co-operation and Development: Health at a glance 2007: Focus on Quality of Care. OECD 2007: I- 194. ISBN 9789264027329

3. Carthy P, Harvey I, Brawn R, Watkins Ch: A study of factors associated with costs and variation in prescribing among GPs. Fam Pract 2000, 17:36-4I.

4. Hogerzeil $\mathrm{H}$ : Promoting rational prescribing: an international perspective. $\mathrm{Br} J$ clin Pharmac 1995, 39: I-6. 
5. O' Mahony D, Galagher PF: Inapprpriate prescribing in the older population: need for new criteria. Age and ageing 2008, 37:|38-|4|

6. Howie JG: Clinical judgment and antibiotic use in general practice. $B M J$ 1976, 2:106|-1064.

7. Hartley RM, Charlton JR, Harris CM, Jarman B: Patterns of physicians use of medical recourses in ambulatory settings. Am J Public Health 1987, 77:565-567.

8. Carrin G: Drug prescribing a discussion of each variability and (ir) rationality. Health Policy 1987, 7:73-94.

9. Schumock GT, Walton SM, Park HY, Nutescu EA, Blackburn JC, Finley JM, Lewis RK: Factors that influence prescribing decisions. Ann Pharmacother 2004, 38:557-62.

10. De Bakker D, Coffie D, Heerdink E, Van Dijk L, Groenewegen P: Determinants of the range of drugs prescribed in genera practice: a cross-sectional analysis. BMC Health Services Research 2007, 7:132.

II. Watkins C, Harvey I, Carthy P, Moore L, Robinson E, Brawn R: Attitudes and behavior of general practitioners and their prescribing costs: a national cross sectional survey. Qual Saf Health Care 2003, I 2:29-34.

12. Coleman JS, Katz E, Menzel H: Medical Innovation. A diffusion study Indianapolis: The Bobbs-Merril Company Inc; 2000.

13. Ryan M, Yule B, Bond C, Taylor RJ: Scottish general practitioners' attitudes and knowledge in respect of prescribing costs. BMJ 1990, 300:1316-1368.

14. Bradley C: Factors which influence the decision whether or not to prescribe: the dilemma facing general practitioners. BrJ Gen Pract 1992, 42:454-458.

15. Muijrers P, Grol R, Sijbrandij J, Janknegt R, Knottnerus J: Differences in prescribing between GPs. Impact of the cooperation with pharmacists and impact of visits from pharmaceutical industry representatives. Fam Pract 2005, 22:624-630.

16. European Observatory on Health Systems and Policies: HiT Summary, Cyprus. Copenhagen 2004 [http://www.euro.who.int/Document/ E85255sum.pdf]. (Accessed on 0I/03/2009)

17. Prosser H, Almond S, Walley T: Influences of GP's decision to prescribe new drugs - the importance of who says what. Fam Pract 2003, 20:61-68.

18. Jones M, Greenfield S, Bradley C: Prescribing new drugs: qualitative study of influences on consultants and general practitioners. BMJ 200I, 323:I-7.

19. National Organization for Medicines: Data regarding Adverse Drug Reactions Reports: 2004-2007. Athens, Greece [http://eof3.eof.grl assets/l6selEOF.pdf]. (Accessed on 05/03/2009)

20. Buusman A, Andersen M, Merrild C, Elverdam B: Factors influencing GPs' choice between drugs in a therapeutic drug group. A qualitative study. Scandinavian journal of Primary Health Care 2007, 25:208-213.

21. Reichert S, Simon T, Halm E: Physicians' Attitudes about prescribing and knowledge of the costs of common medications. Archives of Internal Medicine 2000, 160:2799-2803.

22. Barrett LL: Physicians' attitudes and practices regarding generic drugs. 2005 [http://assets.aarp.org/rgcenter/health/ phys generic.pdf]. (Accessed on I4/03/2008)

23. Kersnik J, Peklar J: Attitudes of Slovene general practitioners towards generic drug prescribing and comparison with international studies. J Clin Pharm Ther 2006, 31 1:577-583.

24. Arroll B, Goodyear-Smith F, Patrick D, Kerse N, Harrison J, Halliwell J, Pearson J, Lay-Yee R, von Randow M: Prescribing Information Resources: Use and preference by general practitioners: An exploratory survey of general practitioners: The overview Report to the Ministry of Health, Wellington, New Zealand, Ministry of Health; 2005.

25. Bowling A: Research Methods in Health. Investigating health and health services second edition. New York, USA, Open University Press: 2002.

\section{Pre-publication history}

The pre-publication history for this paper can be accessed here:

http://www.biomedcentral.com/1472-6963/9/150/pre pub
Publish with Biomed Central and every scientist can read your work free of charge

"BioMed Central will be the most significant development for disseminating the results of biomedical research in our lifetime. "

Sir Paul Nurse, Cancer Research UK

Your research papers will be:

- available free of charge to the entire biomedical community

- peer reviewed and published immediately upon acceptance

- cited in PubMed and archived on PubMed Central

- yours - you keep the copyright
BioMedcentral 